\title{
Value resonance and value framing effects on voting intentions in direct-democratic campaigns
}

\author{
Schemer, C ; Wirth, Werner ; Matthes, J
}

\begin{abstract}
This study offers insights into how news media frames interact with existing value orientations in shaping voter preferences. It is assumed that a framing effect should be more pronounced when frames in the news resonate with people's existing value predispositions. These assumptions were tested in a real-world setting of a political campaign dealing with the issue of naturalization of immigrants. Based on a data set in which the data of a two-wave panel survey were matched with content analytic data, the present research demonstrated frame-resonance effects for news reporting about the pro campaign. That is, framing the issue in terms of the notion that people should have the final say in naturalization procedures shaped voting preferences only for voters whose basic values of social order, tradition, and security (high authoritarians) were touched. In contrast, a main effect of the opponents' framing in the news on voting preferences was found. Thus, the majority followed the framing of the opponents who put emphasis on a fair and pragmatic solution of the naturalization issue.
\end{abstract}

DOI: https://doi.org/10.1177/0002764211426329

Posted at the Zurich Open Repository and Archive, University of Zurich ZORA URL: https://doi.org/10.5167/uzh-53987

Journal Article

Accepted Version

Originally published at:

Schemer, C; Wirth, Werner; Matthes, J (2012). Value resonance and value framing effects on voting intentions in direct-democratic campaigns. American Behavioral Scientist, 56(3):334-352.

DOI: https://doi.org/10.1177/0002764211426329 


\title{
Value Resonance and Value Framing Effects on Voting Intentions in Direct-Democratic Campaigns
}

\section{Christian Schemer', Werner Wirth', and Jörg Matthes}

\begin{abstract}
This study offers insights into how news media frames interact with existing value orientations in shaping voter preferences. It is assumed that a framing effect should be more pronounced when frames in the news resonate with people's existing value predispositions. These assumptions were tested in a real-world setting of a political campaign dealing with the issue of naturalization of immigrants. Based on a data set in which the data of a two-wave panel survey were matched with content analytic data, the present research demonstrated frame-resonance effects for news reporting about the pro campaign. That is, framing the issue in terms of the notion that people should have the final say in naturalization procedures shaped voting preferences only for voters whose basic values of social order, tradition, and security (high authoritarians) were touched. In contrast, a main effect of the opponents' framing in the news on voting preferences was found.Thus, the majority followed the framing of the opponents who put emphasis on a fair and pragmatic solution of the naturalization issue.
\end{abstract}

\section{Keywords}

framing effects, values, value resonance, voting intentions

Research from several decades has demonstrated that values are important backstops of political beliefs and opinions (Feldman, 2003; McClosky \& Zaller, 1984). Values can be considered as stable guiding principles that are ordered hierarchically. More precisely, values refer to desirable goals that transcend specific situations

\footnotetext{
'University of Zurich, Switzerland

${ }^{2}$ University of Vienna, Austria

Corresponding Author:

Christian Schemer, Institute of Mass Communication and Media Research, University of Zurich, Andreasstrasse 15, CH-8050 Zurich, Switzerland

Email: ch.schemer@ipmz.uzh.ch
} 
(Kluckhohn, 1951; Rokeach, 1973; Schwartz, 1992). Public opinion surveys clearly demonstrate that cherished values shape opinions toward public policy issues. For instance, traditionalism and individualism are important predictors of people's opinion in the abortion discourse (Ball-Rokeach, Power, Guthrie, \& Waring, 1990). Given that people stick to their cherished values in political debates, it is no surprise that communicators regularly draw on the power of value-based language to persuade them (Domke, McCoy, \& Torres, 1999; Gamson, 1992). Or, as Nelson and Garst (2005, p. 490) put it "values, therefore, are powerful and reliable weapons in the persuader's arsenal."

Previous research has convincingly demonstrated that communicators are more likely to affect opinion formation of audience members when they frame a political issue in terms of specific values (Shah, Domke, \& Wackman, 1996; Shen \& Edwards, 2005). This kind of strategic communication has also been termed value framing (Ball-Rokeach et al., 1990; Chong \& Druckman, 2007b; Shah et al., 1996). Value frames involve linking value positions to the construction of political debates to provide a compelling interpretative framework that facilitates the understanding of a given policy conflict (Ball-Rokeach et al., 1990; Domke, Shah, \& Wackman, 1998). Typically, value frames depict debates about public policy issues as clashes of deep-rooted values. In these debates, political actors compete for the "legitimacy of one definition of morality and/or competence over another in the struggle to win or control scarce resources" (Ball-Rokeach et al., 1990, p. 254).

Experimental studies suggest that associating political positions to basic values activates value orientations, which in turn serve as easily accessible heuristics shaping people's interpretations and judgments of political issues (Domke et al., 1998; Shah et al., 1996; Shen \& Edwards, 2005). Based on this activation-accessibility explanation, most studies have shown that framing an issue in terms of values can enhance the accessibility of this value position, thereby affecting the judgments about gay rights (Brewer, 2003), immigration (Domke et al., 1999), attitudes toward welfare policy (Shen \& Edwards, 2005), or candidate decision making (Shah et al., 1996).

Although the cumulative evidence of previous studies suggests that framing effects can be quite powerful, some scholars argue that the conditions simulated in laboratory settings do not compare with real-life political communication (Chong \& Druckman, 2007a, 2007b; Druckman, 2004; Kinder, 2007). Accordingly, communication in real campaigns is two-sided, whereas most experiments expose subjects to one-sided communication. Additionally, in most experiments individuals are exposed to a single news story, whereas in reality the audience is exposed to hundreds of stories in the course of a political campaign. Finally, in real campaigns individuals are involved in interpersonal communication, which can correct media framing effects. Consequently, Kinder (2007, p. 158) has argued that these findings "do not speak convincingly to the presentation of frames in everyday life." As a reaction to these shortcomings, scholars have called for studies that strengthen the external validity by exploring value framing effects in the context of real campaigns or by using more representative samples (Kinder, 2007; Matthes, 2008; Richardson, 2005). This is the starting point of the 
present study. It extends previous research by testing value framing effects outside the laboratory. Specifically, by combining a content analysis with data from a panel survey, the study tests the interplay of value frames in the news and the value orientations of audience members.

\section{Literature Review}

A plethora of studies have shown that news media's emphasizing a specific issue while ignoring others strongly influences people's thinking and judgments of political issues (for an overview, see Chong \& Druckman, 2007b; Entman, 1993; Iyengar, 1991; Matthes, 2008; Nelson, Oxley, \& Clawson, 1997). Dozens of experiments have found that the framing of news stories in terms of deep-rooted political values can directly shape public opinion about different attitudinal objects, such as political candidates (Shah et al., 1996), ethnic minorities (Domke et al., 1999; Igartua \& Cheng, 2009), political interest groups (Nelson, Clawson, \& Oxley, 1997), welfare policy (Shen \& Edwards, 2005), or mandatory minimum sentencing (Gross, 2008).

\section{Boundary Conditions of Framing Effects}

However, additional research indicates that audience members differ in their susceptibility to value framing effects (see Druckman, 2001, for an overview). A bulk of studies convincingly demonstrates that value orientations (Shah et al., 1996; Shen \& Edwards, 2005), existing attitudes (Brewer, 2001; Keum et al., 2005), and political sophistication (Barker, 2005; Brewer, 2003) moderate framing effects on judgments about public policy issues.

For instance, findings by Shah and colleagues (1996) suggest that individuals are motivated processors who interpret news items against the background of their own self-concept. In a first step, they showed that the framing of a news story about health care significantly affected the interpretation of the story and subsequent decision making. One group of subject read a news story framed as a conflict of values, the other group read the story framed in material terms. The value frame addressed the health care issue as a matter of morals and human rights. In the material frame condition, the story was "presented in terms of economics, expedience, and practicality" (Shah et al., 1996, p. 520). The results showed that the recipients of the value frame interpreted the news story in terms of values, whereas the readers of the material frame formed a pragmatic interpretation of the health care issue. To investigate the role of value orientations in thinking, the authors relied on two different groups of respondents: undergraduate students and evangelical Christians. As expected, the authors found that the latter group was more likely to interpret the news story in moral terms, whereas the students relied on a pragmatic interpretation.

A study by Shen and Edwards (2005) in the context of the welfare reform showed that message recipients who endorsed individualistic values were influenced by a news story that frames welfare recipients as self-reliant individuals who should be 
required to work to improve their situation. Other studies also suggest that value frames that resonate with individuals' predisposition are more likely to shape the interpretation and judgments about an issue compared to appeals that do not resonate with predispositions (Domke et al., 1999; Keum et al., 2005).

The reason for this value framing resonance effect is that existing value predispositions make value-laden considerations more accessible because they are in a state of chronic accessibility (Shen \& Edwards, 2005). In other words, when message recipients are exposed to value-laden frames in the news that correspond with their cognitive value structure, then their value-laden considerations are more easily activated and, thus, more accessible for judgment formation compared to message recipients who are low in chronic accessibility of this value orientation. Put differently, temporal accessibility induced by the media frame and chronic accessibility due to the existing value structure exert additive effects on judgment formation. ${ }^{1}$

\section{Need for Nonexperimental Evidence in the Study of Framing Effects}

So far, framing effects research has produced valuable findings about the processes and conditions that contribute to variability in public opinion about policy issues. A main caveat of extant research refers to the external validity of findings (Kinder, 2007; Matthes, 2008; Richardson, 2005; Shen \& Edwards, 2005). Specifically, Richardson (2005) argues that the use of a convenience sample "limits the ability to generalize from a specific message to a targeted message population" (p. 522). Matthes (2008) adds that the failure to consider real-world contexts may result in an overrating of media power to manipulate public opinion (see also Kinder, 2007). Two other issues have been brought up that question the mundane reality of the experimental results presented in the previous sections (see also Druckman, 2001).

On one hand, most studies relied on one-trial exposure to a frame in the news. Thus, we know comparably little about repeated exposures and cumulative effects (but see Chong \& Druckman, 2007a). At least some experiments suggest that direct effects of framing on attitudes are weak or even absent when recipients are exposed to crosscutting communication (e.g., pro and con arguments) about an issue (Brewer, 2001; Cho, De Zuniga, Shah, \& McLeod, 2006; Lee, McLeod, \& Shah, 2008; Richardson, 2005). On the other hand, previous research gives only scant indication of the longevity of framing effects (Sotirovic, 2000). Only a few studies include tests of long-term effects of experimental framing manipulations. De Vreese (2004) showed that framing effects vanish within 1 week. Another study provides tentative evidence that at least strong frames may survive more than 3 weeks even if their impact decreased (Tewksbury, Jones, Peske, Raymond, \& Vig, 2000). All these findings referred to above are limited with respect to the external validity and generality of framing effects. Therefore, the aim of our study is to test value framing effects in an externally valid setting. Specifically, the present study will test the effects of the interplay of value frames and individuals' 
value predispositions on public opinion in the course of real political campaign about immigration policy.

\section{Theoretical Assumptions}

The present research is based on the assumption that political actors or parties typically invoke deep-rooted values in their attempt to promote a particular definition of an issue in the public (Ball-Rokeach et al., 1990; Entman, 1993). By associating policy issues to values political actors try to legitimize certain policy positions and, ultimately, to gain support for their position. Even if political actors do not directly frame their messages in terms of basic values, journalists tend to structure the political discourse in terms of such values (e.g., Lee et al., 2008). The framing of an issue in terms of cherished values promotes the activation of values in the cognitive structure of recipients resulting in a temporal accessibility of those beliefs. Provided that these values are accessible and applicable to a given attitude object, individuals are likely to use these values in subsequent information processing and judgment formation (Domke et al., 1999; Iyengar, 1991).

This reasoning suggests a main effect of value frames on opinion formation. However, most studies that found main effects of value-laden frames exposed subjects to news stories that were framed in a one-sided fashion (e.g., Igartua \& Cheng, 2009; Shen \& Edwards, 2005). In contrast, experiments in which subjects were exposed to two-sided framing (i.e., stories that contain pro and con frames) failed to show main effects of the value frames (Brewer, 2001; Cho et al., 2006; Lee et al., 2008; Richardson, 2005). In real campaigns, the exposure to one-sided or two-sided communication may vary from individual to individual. Given that in political contests at least a part of the audience is exposed to a one-sided framing in the news, it can be assumed that value frames exert a direct effect on judgment formation. Therefore, we hypothesize a main effect of value frames on people's political preferences (Hypothesis 1).

In addition, some studies found that value frames exert a stronger attitudinal impact when there is a match between value endorsement and value framing in the news (Domke et al., 1999; Shen \& Edwards, 2005). Put differently, when value frames in the news and value orientations resonate, then political messages will be more persuasive. However, the direction of the effect strongly depends on the value that people endorse and the direction of the value appeal. For instance, political messages about a policy program (e.g., immigration policy restriction) are more persuasive for people whose value orientations already favor this position (e.g., conservative individuals). Thus, this thread of research suggests that value resonance - the match of value frame and value orientation - promotes persuasion. Therefore, the second hypothesis states that value frames that match with an existing value structure have a stronger impact on political preferences than value frames that do not match or mismatch with existing value orientations (Hypothesis 2). 


\section{Method}

\section{Context of the Study}

The present study tests value framing effects in the context of a campaign dealing with the issue of immigration. More specifically, in this campaign the populist right in Switzerland fought for their initiative "for democratic naturalizations." In Switzerland, the naturalization procedure is not only the result of an administrative process, but also a political decision that varies considerably in different municipalities. The naturalization of immigrants can be based on decisions by a general assembly of local citizens, local parliaments or executives, or even by popular votes at the ballot box. In some municipalities, naturalization requests were rejected without justification. Therefore, the federal court decided that the rejection of naturalization requests required a justification. Furthermore, the court specified that a justification was not possible in a direct-democratic vote.

As a reaction to this decision, the populist right launched its popular initiative. They considered the court decision as a paternalistic act against the will of the Swiss people. Consequently, they claimed that the people should have the right to decide about the naturalization procedure (see Hänggli \& Kriesi, in press). Furthermore, the initiative denies applicants to appeal a rejection of their naturalization request. The proponents of this initiative emphasized the importance of and respect for the people's will in naturalization decisions (i.e., the "people final say" frame; see Hänggli \& Kriesi, in press). At the same time, they warned against naturalizations and naturalization of criminals when the naturalization procedure becomes a purely administrative act that cannot be influenced by the Swiss people (i.e., the "mass naturalization" frame). These appeals clearly address values of traditionalism, social dominance, and security. Therefore, this pattern of argumentation of the populist right can be considered as a value frame (also see Gerth \& Siegert, in press; Matthes, in press; Hänggli \& Kriesi, in press; Wettstein, in press).

The opponents of the initiative formed a loose front of the political left, liberals, and Christian Democrats. There were different committees launching their own campaign with different strategies. However, all of these political actors countered the initiative of the populist right. Their main arguments stressed the need to guarantee a fair naturalization procedure in accordance with the rule of law (i.e., the "rule of law" frame). Discriminatory decisions should be ruled out. This pattern of arguments was a mixture of material and value framing in the terminology of previous studies (Domke et al., 1998; Shah et al., 1996). It was material in nature because it simply argued that democratic naturalizations did not conform to the rule of law and, therefore, could not be implemented. The opponents' argumentation was also value-laden because it was stated that democratic naturalizations were unfair and contradicted human rights. The naturalization initiative was submitted to the Swiss people on June 1, 2008, and was rejected by a majority of $63.6 \%$ of the voters. 


\section{Content Analysis of News Media}

For the content analysis of the news media, a total of 947 articles were coded between March 1 and May 31 (the day before the vote). The most important elite, free, and regional newspapers, tabloid news, Public Service TV news, and TV shows in the German- and the French-speaking part of the country were selected. ${ }^{2}$ The basic level of the content analysis was the argument expressed by a political actor or a journalist. An argument is defined as a verbalization of a specific point of view in which a claim is expressed with a certain evaluation (also see Matthes, in press). This understanding is largely consistent with the frame conceptualization by Entman (1993; see for a definition of single frame elements Matthes \& Kohring, 2008). Often arguments are accompanied by propositions of possible solutions or the reasons of the problem. However, in our case, the solution that was proposed by proponents was nearly always embedded in the problem definition. According to the populist right, the adoption of the initiative favoring democratic naturalization is the solution to the problem. In contrast, for the opponents this solution was the main problem because in their view the naturalization proposal was incompatible with the rule of law. Therefore, the main patterns of arguments used by proponents and opponents form the frames employed by both sides that also occurred in the news media (see the Results section for the description of the specific frames). In sum, 4,496 arguments were coded by 10 trained coders. ${ }^{3}$ In contrast to Hänggli and Kriesi (in press) and due to problems of multicollinearity in data matching, we only distinguish pro (i.e., "rule of law") from contra (i.e., "people final say" plus "mass naturalization") framing.

\section{Panel Survey}

A two-wave panel survey by means of computer-assisted telephone interviews was conducted. The first wave was fielded from April 7 to 25, $2008(N=1,251)$. The second interview took place after the vote (i.e., after June 1, 2008; $N=999$ ). The sample was recruited applying a random-quota procedure and is representative in terms of sex (51.3\% female), age ( $M=48.5, S D=16.8)$, and residence. However, young people and people with lower educational degrees are slightly underrepresented in the second panel wave.

\section{Measures}

The central dependent variable was voting intention, measured with a single item on a 5-point scale (strongly in favor, slightly in favor, undecided/do not know, slightly opposed, strongly opposed). The dependent variable was asked in both panel wave and produced a test-retest reliability of .70. As independent variables, value orientations were assessed by using a three-item short form of right-wing authoritarianism (Altemeyer, 1996) (Cronbach's alpha $=.64$ ). This construct was measured because 
high authoritarians have been shown to adhere to traditional values, tend to denigrate out-groups and minorities, and are submissive to authority figures.

A quite important measure was the use of or reliance on different communication channels and mass media. To link the panel study with the content analysis of the news media, we asked for the specific medium (TV and newspaper) that the interviewees used to keep informed during the campaign. As additional controls, we relied on measures of sex, age, education (highest educational degree), and political orientation on a 10-point scale (1 denotes left, 10 denotes right).

\section{Data Analysis}

The content analysis and the panel survey data were matched on the individual level. In this procedure, every survey participant was assigned a value representing the frequency with which she or he was confronted with a certain frame of the pro or con camp. This matching was based on the specific news media use patterns that the survey respondents reported. The same procedure applies for the frequency of reporting of different news sources used by the audience and for different time intervals (before the first panel wave and between the first and the second panel wave). Consequently, the participants of our survey are matched with the media input that they were most likely to be confronted with. A similar procedure has been successfully adopted in previous studies (e.g., Dalton, Beck, \& Huckfeldt, 1998; Matthes, 2008). The main advantage of this procedure is that voting preferences can be regressed on the specific content of news stories that people were exposed to before they were interviewed (Shoemaker \& Reese, 1990).

\section{Results}

\section{Content Analytic Results}

In a first step, the content analytic data are presented in order to shed light on the media framing of proponents and opponents of the initiative. Table 1 shows the relative frequency of the most important arguments expressed in the campaign. The table indicates that the most important argument in the campaign overall was the central argument of the opponents. It emphasized that the rule of law should apply in naturalization procedures. When arguments against democratic naturalizations occurred in the news media, then in more than half of the cases $(51.8 \%)$ they referred to the rule of law. The second most important argument against democratic naturalizations stated that arbitrary and discriminating naturalization decision should be avoided.

The most important argument of the supporters claimed that the Swiss people should have the final say in naturalization procedures. The frequency of this argument relative to all other pro arguments makes up a share of $43.4 \%$. Their second and third most important arguments referred to the prevention of mass naturalizations and legal aspects of their initiative. These figures show that the discourse was structured by two 
Table I. Relative Frequency of Pro and Con Arguments in News Media Reporting

\begin{tabular}{lc}
\hline Arguments & Percentage relative to all arguments \\
\hline Pro arguments & 41.6 \\
People should have final say & 18.1 \\
Prevent mass naturalizations & 8.8 \\
Democratic naturalizations not appealable & 8.1 \\
Delinquent immigrants & 5.1 \\
Other pro arguments & 1.5 \\
Con arguments & 58.4 \\
Rule of law & 30.3 \\
No arbitrary decisions discriminating applicants & 13.9 \\
Attacks against proponents & 7.9 \\
Current naturalization practice sufficient & 3.1 \\
Other con arguments & 3.2 \\
\hline
\end{tabular}

main frames. The framing of the populist right that promoted the idea that the people should have the final say. This framing was most dominant in the discourse promoting the popular initiative. The other arguments seldom occur without reference to this main frame. Thus, the central organizing idea structuring the argumentation of the supporters was that the Swiss people should have the final say. Therefore, their strategy frame is henceforth termed "people final say."

When the frequency of occurrence of the main arguments of the opponents' news media framing is considered, then a similar picture emerges. Their argumentation was structured by the claim that naturalization procedures should be in accordance with the rule of law (e.g., with human rights) and that applicants should not be discriminated. Therefore, this framing is henceforth termed "rule of law" frame. For the subsequent analysis, the two main arguments forming the proponents' and opponents' frames were summed up to an index "final say of the people" and "rule of law," respectively. The "people final say" frame includes the "mass naturalization" frame distinguished by Hänggli and Kriesi (in press). These content analytic categories are then matched to the survey data and serve as independent variables.

\section{Hypothesis Tests}

Given the nature of the data, the analysis is based on generalized estimating equations (GEE) with an identity link function. GEE are a generalization of the general linear model (GLM; see also Liang \& Zeger, 1986). Specifically, GEE provide an extension of the GLM to longitudinal data when basic assumptions of the GLM are violated (e.g., nonnormal distribution of the dependent variable, correlations between the residuals of independents and the dependent variable, or inhomogeneity of the variance for the range of the dependent variable). For the subsequent analysis, the form 
Table 2. Results of a Generalized Estimating Equation (GEE) Model Testing Framing Effects on Voting Preferences

\begin{tabular}{lcccc}
\hline Independent Variable & $\begin{array}{c}\text { Model I } \\
\text { Estimates (SE) }\end{array}$ & $\begin{array}{c}\text { Model } 2 \\
\text { Estimates (SE) }\end{array}$ & $\begin{array}{c}\text { Model 3 } \\
\text { Estimates (SE) }\end{array}$ & $\begin{array}{c}\text { Model 4 } \\
\text { Estimates (SE) }\end{array}$ \\
\hline Constant & $3.40(.04)^{* * *}$ & $1.71(.26)^{* * *}$ & $2.07(.29)^{* * *}$ & $2.02(.29)^{* * * *}$ \\
Sex & & $.09(.08)$ & $.09(.08)$ & $.10(.08)$ \\
Age & & $.01(.01)^{*}$ & $.01(.01)$ & $.01(.01)$ \\
Education & & $.45(.07)^{* * *}$ & $.43(.07)^{* * *}$ & $.44(.07)^{* * *}$ \\
Left-right self-positioning & & $-.21(.02)^{* * *}$ & $-.21(.02)^{* * *}$ & $-.21(.02)^{* * *}$ \\
Authoritarianism & $-.29(.05)^{* * *}$ & $-.28(.05)^{* * *}$ & $-.28(.05)^{* * *}$ \\
Time & $.51(.05)^{* * *}$ & $.32(.09)^{* * *}$ & $.33(.09)^{* * *}$ \\
Pro frame "people final say" & & & $-.52(.40)$ & $-.46(.39)$ \\
Con frame "rule of law" & & & $.76(.29)^{* * * *}$ & $.66(.29)^{* *}$ \\
Pro Frame $\times$ Authoritarianism & & & & $-.27(.09)^{* *}$ \\
Con Frame $\times$ Authoritarianism & & & & $.09(.35)$ \\
QICC & $3,047.17$ & $2,334.37$ & $2,311.76$ & $2,305.73$ \\
Corrected pseudo- $R^{2}$ & & .23 & .25 & .26 \\
\hline
\end{tabular}

Entries are unstandardized regression coefficients (standard errors are in parenthesis); QICC is the corrected quasi-likelihood under the independence model criterion and is a derivation of Akaike's information criterion for GEE.

${ }^{*} p<.10$. ${ }^{* *} p<.05$. *** $p<.01$.

of the serial correlation is assumed to be first-order autoregressive, although GEE yield consistent estimates of the regression coefficients even without stringent assumptions about the actual correlation structure (Liang \& Zeger, 1986). Similar to mixed models, the fit of these models can only be estimated in relation to simpler models. Therefore, in a first step, an intercept-only model is estimated (see Table 2, second column). With the integration of additional independent variables the model should improve in predictive power. The results of these analyses are depicted in Table 2.

In the second model, the demographics and political predispositions are introduced as predictors. These predictors improve the explanatory power that can be seen when one compares the decrease in QICC (corrected quasi-likelihood under independence model criterion) or the corrected pseudo- $R^{2}$. Although age and sex do not predict people's voting preferences, education and political predispositions do. In particular, loweducated, conservative, and authoritarian respondents favor the proposal to introduce democratic naturalizations. In addition, the significant time effect indicates that people moved more to a rejection of the initiative in the course of the campaign.

The third model tests the effects of the value framing in the news. It was assumed that the value frames structuring the discourse in the news media should directly affect voting preferences. This hypothesis receives partial support. On one hand, the news framing of the adversaries of the popular initiative increases the opposition to the 


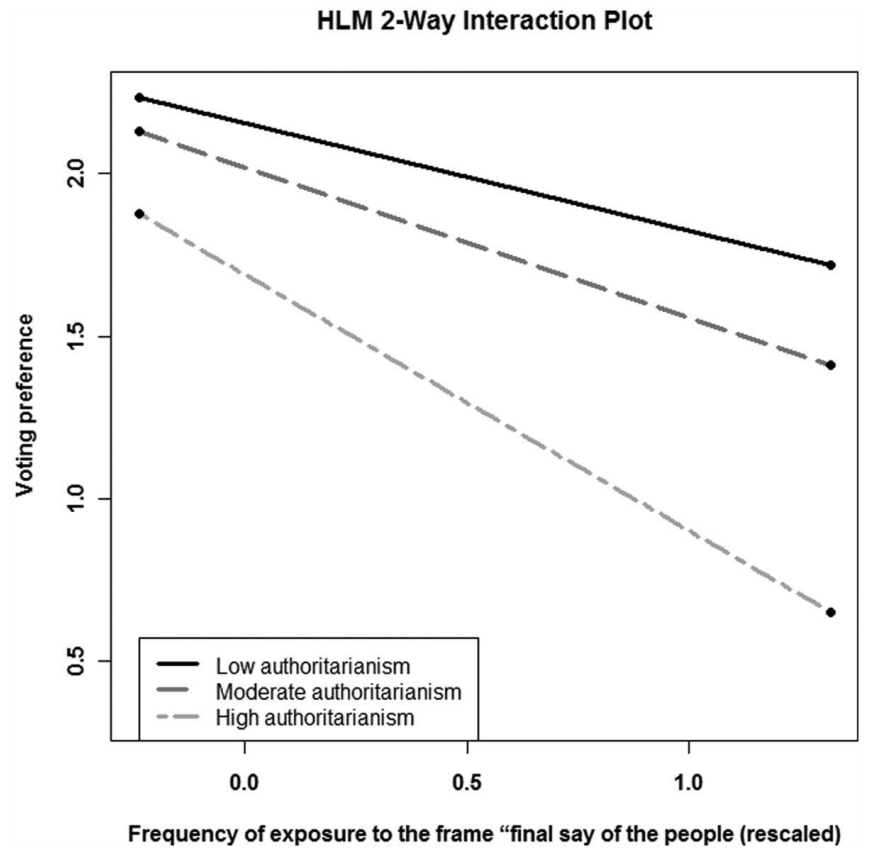

Figure I. Interaction effect of news framing and authoritarianism on voting preferences Small values of the voting preference indicate support for the proposal.

policy proposal. Audience members exposed to a news discourse that emphasized the rule of law and condemned discrimination were more likely to reject the proposal. On the other hand, we failed to find a direct effect of the framing of the issue in terms of people's final say on voting preferences. Put differently, the news framing of the proponents of the popular initiative in the media did not affect voting preferences directly. This result contradicts the first hypothesis.

The second hypothesis states that news frames that match with an existing value structure have a stronger impact than value frames that mismatch. Thus, an interaction effect of value predisposition and news framing is hypothesized. Again, this hypothesis is partially supported. An interaction effect of the "final-say" frame and authoritarianism is obtained in the fourth model. To facilitate the interpretation, Figure 1 shows the interaction effect graphically. This figure indicates that the proponents' framing of the initiative affected only the voting intentions of high authoritarians. This is confirmed by an additional test of the slope of the framing effect for high authoritarians $(z$ $=-2.44, p<.05)$. Although the slope for moderate and low authoritarians also shows a decreasing trend with more frequent exposure to the final say frame, their voting preferences were not affected ( $z=-0.81$ for moderates, and $z=-1.16$ for low authoritarians). 
This finding provides evidence for the assumption of value resonance: When the news framing (i.e., the final say frame) and value orientation (i.e., high authoritarianism) matched, then support for the proposal of the populist right was high.

The second interaction term was not significant. Thus, authoritarianism did not moderate the effect of the "rule of law" frame on voting preferences. This result lends support to the notion that value predispositions and frames in the news that mismatch with existing value predispositions exert independent effects on voting preferences. Interestingly, this finding implies that high authoritarians were influenced by the framing of both parties, that is, proponents and opponents. Thus, even if their value predisposition made them responsive to value appeals of the populist right, they were obviously not so closed-minded to be immune against the news framing of the opponents. This finding is discussed in depth in the following section.

\section{Discussion}

The present study demonstrates direct value framing and resonance effects in the context of a direct-democratic campaign. Specifically, it shows direct framing effects of the news reporting about naturalization in terms of the rule of law on voting preferences. Thus, the frequent exposure to the "rule of law" frame in the news increased the tendency of the voters to reject a more restrictive naturalization procedure. In contrast, the value-laden framing of the supporters of this proposal affected only the voting preferences of authoritarian individuals. This confirms the value-resonance hypothesis; that is, value appeals are more persuasive when value-laden messages match with the value orientations of recipients. In sum, the present findings corroborate the results of research that has been conducted exclusively in the laboratory (e.g., Lee et al., 2008; Shen \& Edwards, 2005). Even under externally valid conditions of a realworld campaign that is characterized by repeatedly cross-cutting communication, selective exposure, and interpersonal influences, news framing effects on public opinion do occur.

One of the main advantages of the present study was its unique research design. Whereas in most media effects studies in field settings attitudes were regressed on measures of media exposure, this study used measures of media content from a content analysis that was individually linked to the survey data. This procedure has the benefit that one knows the valence of the media content that is likely to affect attitudes of audience members. In contrast, studies that solely rely on measures of media use obviously confound the effects of exposure to the news with the effects of specific media content to which individuals are exposed. For campaigns with one-sided or consonant media reporting, there may be no difference between the present approach and analyses using only exposure measures. However, when communication is two-sided, the latter approach may underestimate real campaign effects. The reason is that the effects of mutually neutralizing communication effects remain unnoticed when public opinion is regressed on news exposure. As has been highly recommended by some scholars, 
this problem can be circumvented by integrating message content into survey data sets (Shoemaker \& Reese, 1990).

Our study contradicts the findings of previous research which failed to find direct framing effects on policy attitudes (Domke et al., 1998, 1999; Shah et al., 1996). However, these studies were single-exposure experiments in which message recipients were exposed to a single news story that presented an issue in a controversial way. Given the lack of a clear attitudinal direction of the article in these experiments, subjects received no direct cue that may have guided their opinion formation. In contrast, framing experiments exposing individuals to one-sided communication clearly demonstrate that the news framing have a direct attitudinal impact (e.g., Igartua \& Cheng, 2009; Shen \& Edwards, 2005).

Thus, the study adds to extant research by showing that even when audience members are exposed to two-sided communication in a real campaign, the repeated framing of an issue can finally shape preferences of voters. Thus, the context of real campaigns does not consequentially eliminate the effects of news framing on audience members' preferences. This argument has been put forward by some scholars that have questioned the artificiality and lack of external validity of experiments (e.g., Druckman, 2001; Kinder, 2007). This is both good and bad news in normative terms. It is good news because the study shows that voters cannot be simply manipulated by symbolic political propaganda. In contrast, judgment formation of the majority of the voters was influenced by the news framing that was promoted by the opponents of the policy proposal. However, it is also bad news because the news framing of the proponents of democratic naturalizations exploited existing value predispositions of authoritarian individuals. Thus, symbolic politics propaganda is likely to keep prejudice against outgroups alive, at least for a minority of the population (Sears, 1994).

The previous reasoning suggests that voters found the con argumentation more convincing and more persuasive. There is ample experimental evidence showing that message recipients are active receivers deliberating about the importance of different considerations in the context of a given problem (Brewer, 2001; Nelson, Oxley et al., 1997). In this perspective, framing effects are likely to be based on an explicit learning process in which people deliberate about pro and con arguments. However, other scholars argue that people simply follow the framing of the loudest political actors (Chong \& Druckman, 2007a; Zaller, 1992), that is, in the present study the campaign of the opponents. In the present study, it cannot be distinguished whether voters consciously evaluated the persuasiveness of the news framing, whether they simply embraced the "loudest" position, or whether they followed group cues that were present in the news. Additional evidence from experiments is needed to elucidate the processes that may have produced the effects found in the present analysis. Specifically, future studies should explicitly test whether or for whom framing effects are based on automatic accessibility or on belief importance.

Such conclusions notwithstanding, the finding that direct and interactive effects are obtained for different framing strategies requires further justification. Specifically, one may ask why the framing of the supporters of the proposal did not produce main 
effects. Furthermore, one may also wonder why the effect of the rule-of-law frame was not moderated. In the present campaign, the value-laden appeals of the supporters of democratic naturalizations were likely to be too extreme for the majority of the voters. Most voters may have realized that this popular initiative is only an attempt of the populist right to keep the immigration issue on the political agenda. Thus, when voters considered the popular initiative in more detail, they must have recognized that the initiative was in reality nothing more than populist propaganda to discriminate outgroups. As voters may have exposed the initiative as symbolic politics that must not be taken seriously, they may have rejected it right away. A similar reasoning is put forward by Kinder (2007, p. 156): He argues that "if frames wander too far afield, they will be rejected." And even if the people generally favored a more restrictive naturalization policy, they might have considered this proposal as difficult to implement. Therefore, most voters were not directly affected by the proponents' framing of the proposal.

However, this framing found its most fertile soil in a minority of authoritarian voters. Their value predisposition resonated fairly well with the argumentation of the populist right. More precisely, people endorsing authoritarian values adhere to traditionalism, tend to discriminate out-groups, and are submissive to authority figures (Altemeyer, 1996). These needs were clearly satisfied by the present proposal because the procedures would have endowed the Swiss people as the dominant group with a means to dominate naturalization applicants. Given that this argumentation corresponded with the value structure of authoritarians, they were more susceptible to the framing of the supporters compared to low or moderate authoritarians. Nevertheless, the main effect of the framing of the opponents of the naturalization proposal indicates that also high authoritarians were influenced by this communication strategy, although this framing contradicted their value priorities. How can this finding be explained in the light of the previous argumentation? One possible explanation is that high authoritarians might not be so closed-minded that they automatically reject appeals that do not correspond to their value structure. This account is even more likely to hold when one considers that authoritarians must have received news stories that informed them that a majority of the Swiss people, most parties, and the government recommended the rejection of the proposal. This situation may have produced a conflict in high authoritarians. For instance, compared to most other people, high authoritarians place greater value on group membership (i.e., being Swiss) and are more submissive to authority figures (i.e., the Swiss government) (Altemeyer, 1994).

Part of this reasoning can be corroborated with the present data. In the survey, it was also asked whether voters followed the voting recommendations of parties, the government, or voted in accordance with the Swiss people. The data show that high authoritarians found the governments' voting recommendation $(r=.09, p<.05)$ and the opinion of the Swiss people $(r=.32, p<.01)$ more important as guides for opinion formation compared to moderate or low authoritarians. Being in disagreement with the majority and with important authority figures must have caused dissonance. To solve this dissonance, high authoritarians may have been more attentive to the campaign. This heightened attentiveness and the need for dissonance reduction may have 
made them more susceptible for the news framing of the opponents' campaign. Experimental results also suggest a similar process. For instance, when message recipients are exposed to unexpected message positions of communicators, then message scrutiny is enhanced and strong arguments have a persuasive impact of attitudes (Baker \& Petty, 1994).

Although this study offers important insights into the study of framing effects, some weaknesses must be recognized. In particular, the specific nature of the campaign under investigation makes generalizations difficult. In the present campaign, one camp relied on an obvious value framing strategy, whereas the countercampaign rather employed a mixed-message strategy consisting of material and value frames in communicating their messages. However, there might be campaigns in which value-laden appeals from both sides of the political spectrum collide. Alternatively, one can also imagine campaigns in which only material framing strategies clash. Based on the present findings, one can only speculate about the likely effects of such campaign strategies on voting preferences.

Another caveat of the present study is the strong assumption that the media content that we analytically matched to the survey respondents is really the content that they were exposed to. On one hand, the media content that was treated as the independent variable in the analysis might have been only a reduced amount of the campaign propaganda that individuals really received through communication channels, for example, radio, Internet, or interpersonal communication. The impact of all these sources was not considered in the analysis. On the other hand, the media impact variables that were used may also overestimate the real impact of news reporting of the campaign. Our matching procedure assumed that survey respondents used the news sources regularly. Thus, this suggests that users of daily newspapers are exposed to newspaper information every day. This assumption overlooks that news media users might not have been exposed to these sources as regularly as our matching procedure suggests. Another reason may be that the attention to a given source may have varied considerably from day to day. These sources of variation in our independent variables were not sufficiently considered.

These caveats notwithstanding, the uniqueness of the present research design is a valuable means to unmask media effects that otherwise can only be detected in the laboratory. Therefore, it should also encourage other researchers to use similar designs aiming at the integration of media content and media effects research to test media effects in externally valid settings.

\section{Declaration of Conflicting Interests}

The author(s) declared no potential conflicts of interest with respect to the authorship and/or publication of this article.

\section{Funding}

The author(s) disclosed receipt of the following financial support for the research, authorship, and/or publication of this article: This research was supported by a grant from the 
Swiss National Science Foundation as a part of the project "Challenges to Democracy in the 21 st Century" of the National Center of Competence in Research.

\section{Notes}

1. There is another account for how framing effects occur. This model is called the importance change model (e.g., Nelson, Oxley, \& Clawson, 1997, Slothuus, 2008) and argues that framing effects are not the result of the automatic accessibility of cognitions, but the intentional weighing of certain perspective that is provided by a news article. This is consequential in terms of the normative implications of framing effects. However, to date there are only a few studies that explicitly test whether framing effects result from automatic accessibility or belief importance change. The present research cannot resolve this issue. However, I come back to this issue in the Discussion section dealing with the normative implications of framing effects.

2. More specifically, the content of the following news sources was coded: Tagesschau, Arena, Le journal, SF Rundschau, Infrarouge, Blick, Sonntagsblick, Neue Zürcher Zeitung, NZZ am Sonntag, Tagesanzeiger, Sonntagszeitung, 20 Minuten, Aargauer Zeitung, Basler Zeitung, Berner Zeitung, Neue Luzerner Zeitung, Die Südostschweiz, St. Galler Tagblatt, Le Matin, Le Temps, Tribune de Genève, 24 heures, 20 Minutes, L'Hebdo, Punkt CH, Sonntag (AZ), Die Südostschweiz am Sonntag, and Le Matin Dimanche.

3. The reliability of the coding is .61 (Cohen's Kappa). For the analysis, the specific codes for the arguments were summarized to broader categories (frames). These superordinate categories were less prone to error in the coding procedure (Cohen's Kappa $=.87$ ).

\section{References}

Altemeyer, B. (1994). Reducing prejudice in right-wing authoritarians. In M. P. Zanna \& J. M. Olson (Eds.), The psychology of prejudice. The Ontario symposium (Vol. 7, pp. 131-148). Hillsdale, NJ: Lawrence Erlbaum.

Altemeyer, B. (1996). The authoritarian specter. Cambridge, MA: Harvard University Press.

Baker, S. M., \& Petty, R. E. (1994). Majority and minority influence: Source-position imbalance as a determinant of message scrutiny. Journal of Personality and Social Psychology, 67(1), 5-19.

Ball-Rokeach, S. J., Power, G. J., Guthrie, K. K., \& Waring, H. R. (1990). Value-framing abortion in the United States: An application of media system dependency theory. International Journal of Public Opinion Research, 2(3), 249-273.

Barker, D. C. (2005). Values, frames, and persuasion in presidential cnomination campaigns. Political Behavior, 27(4), 375-394.

Brewer, P. R. (2001). Value words and lizard brains: Do citizens deliberate about appeals to their core values? Political Psychology, 22(1), 45-64.

Brewer, P. R. (2003). Values, political knowledge, and public opinion about gay rights. Public Opinion Quarterly, 67, 173-201.

Cho, J., De Zuniga, H. G., Shah, D. V., \& McLeod, D. M. (2006). Cue convergence. Associative effects on social intolerance. Communication Research, 33(3), 136-154. 
Chong, D., \& Druckman, J. N. (2007a). Framing public opinion in competitive democracies. American Political Science Review, 101(4), 637-655.

Chong, D., \& Druckman, J. N. (2007b). A theory of framing and opinion formation in competitive elite environments. Journal of Communication, 57, 99-118.

Dalton, R. J., Beck, P. A., \& Huckfeldt, R. (1998). Partisan cues and the media. American Political Science Review, 92(1), 111-126.

de Vreese, C. H. (2004). The effects of strategic news on political cynicism, issue evaluations, and policy support: A two-wave experiment. Mass Communication and Society, 7(2), 191-214.

Domke, D., McCoy, K., \& Torres, M. (1999). News media, racial perceptions, and political cognition. Communication Research, 26(5), 570-607.

Domke, D., Shah, D. V., \& Wackman, D. B. (1998). "Moral referendums": Values, news media, and the process of candidate choice. Political Communication, 15, 301-321.

Druckman, J. N. (2001). The implications of framing effects for citizen competence. Political Behavior, 23(3), 225-256.

Druckman, J. N. (2004). Political preference formation: Competition, deliberation, and (ir) relevance of framing effects. American Political Science Review, 98(4), 671-687.

Entman, R. M. (1993). Framing: Toward clarification of a fractured paradigm. Journal of Communication, 43(4), 51-58.

Feldman, S. (2003). Values, ideology, and of political attitudes. In D. O. Sears, L. Huddy, \& R. Jarvis (Eds.), Oxford handbook of political psychology (pp. 477-508). New York, NY: Oxford University Press.

Gamson, W. A. (1992). Talking politics. Cambridge, UK: Cambridge University Press.

Gerth, M. A., \& Siegert, G. (in press). Patterns of consistence and constriction. How news media frame the coverage of direct democratic campaigns. American Behavioral Scientist, $\mathrm{XX}, \mathrm{XX}$.

Gross, K. (2008). Framing persuasive appeals: Episodic and thematic framing, emotional response, and policy opinion. Political Psychology, 29(2), 169-192.

Hänggli, R., \& Kriesi, H. (in press). Frame construction and frame promotion (strategic framing choices). American Behavioral Scientist, XX, XX.

Igartua, J.-J., \& Cheng, L. (2009). Moderating effect of group cue while processing news on immigration: Is the framing effect a heuristic process? Journal of Communication, 59(4), 726-749.

Iyengar, S. (1991). Is anyone responsible? How television frames political issues. Chicago, IL: University of Chicago Press.

Keum, H., Hillback, E. D., Rojas, H., De Zuniga, H. G., Shah, D. V., \& McLeod, D. M. (2005). Personifying the radical. How news framing polarizes security concerns and tolerance judgments. Human Communication Research, 31(3), 337-364.

Kinder, D. R. (2007). Curmudgeonly advice. Journal of Communication, 57, 155-162.

Kluckhohn, C. K. (1951). Values and value orientations in the theory of action. In T. Parsons \& E. A. Shils (Eds.), Toward a general theory of action. Cambridge, MA: Harvard University Press.

Lee, N.-J., McLeod, D. M., \& Shah, D. V. (2008). Framing policy debates. Issue dualism, journalistic frames, and opinions on controversial policy issues. Communication Research, $35(5), 695-718$. 
Liang, K.-Y., \& Zeger, S. L. (1986). Longitudinal data analysis using generalized linear models. Biometrika, 73, 13-22.

Matthes, J. (2008). Media frames and political judgments. Exploring the boundaries of framing effects in a two-wave panel study. Studies in Communication Sciences, 8(2), 101-128.

Matthes, J. (in press). Framing politics: An integrative approach. American Behavioral Scientist, XX, XX.

Matthes, J., \& Kohring, M. (2008). The content analysis of media frames: Toward improving reliability and validity. Journal of Communication, 58, 258-279.

McClosky, H., \& Zaller, J. (1984). The American ethos: Public attitudes toward capitalism and democracy. Cambridge, MA: Harvard University Press.

Nelson, T. E., Clawson, R. A., \& Oxley, Z. M. (1997). Media framing of a civil liberties conflict and its effect on tolerance. American Political Science Review, 91(3), 567-583.

Nelson, T. E., \& Garst, J. (2005). Value-based political messages and persuasion relationships among speaker, recipient, and evoked values. Political Psychology, 26(4), 489-515.

Nelson, T. E., Oxley, Z. M., \& Clawson, R. A. (1997). Toward a psychology of framing effects. Political Behavior, 19(3), 221-246.

Richardson, J. D. (2005). Switching social identities: The influence of editorial framing on reader attitudes toward affirmative action and African Americans. Communication Research, 32(4), 503-528.

Rokeach, M. (1973). The nature of human values. New York, NY: Free Press.

Schwartz, S. H. (1992). Universals in the content and structure of values: Theoretical advances and empirical tests in 20 countries. Advances in Experimental Social Psychology, $25,1-65$.

Sears, D. O. (1994). Symbolic politics: A socio-psychological theory. In S. Iyengar \& W. J. McGuire (Eds.), Explorations in political psychology (pp. 113-149). Durham, NC: Duke University Press.

Shah, D. V., Domke, D., \& Wackman, D. B. (1996). "To thine own self be true": Values, framing, and voter decision-making strategies. Communication Research, 23(5), 509-560.

Shen, F., \& Edwards, H. H. (2005). Economic individualism, humanitarianism, and welfare reform. A value-based account of framing effects. Journal of Communication, 55(4), 795-809.

Shoemaker, P. J., \& Reese, S. D. (1990). Exposure to what? Integrating media content and effects studies. Journalism Quarterly, 67(4), 649-652.

Slothuus, R. (2008). More than weighing cognitive importance: A dual-process model of issue framing effects. Political Psychology, 29(1), 1-28.

Sotirovic, M. (2000). Effects of media use on audience framing and support for welfare. Mass Communication \& Society, 3(2-3), 269-296.

Tewksbury, D., Jones, J., Peske, M. W., Raymond, A., \& Vig, W. (2000). The interaction of news and advocate frames: Manipulating audience perceptions of a local public policy issue. Journalism and Mass Communication Quarterly, 77(4), 804-829. 
Wettstein, M. (in press). Frame adoption in referendum campaigns: The effect of news coverage on the public salience of issue interpretations. American Behavioral Scientist, XX, XX.

Zaller, J. R. (1992). The nature and origins of mass opinion. Cambridge, UK: Cambridge University Press.

\section{Bios}

Christian Schemer (PhD, University of Zurich, 2009) is senior researcher at the Institute of Mass Communication and Media Research, University of Zurich, Switzerland. His research focuses on political persuasion, media effects, and research methodology.

Jörg Matthes (PhD, University of Zurich, 2007) is professor at the Department of Communication, University of Vienna, Austria. His research focuses on public opinion formation, media effects, advertising, and empirical methods.

Werner Wirth (PhD, University of Munich, 1994) is full professor for empirical research at the Institute of Mass Communication and Media Research, University of Zurich, Switzerland. His research focuses on cognitive, affective and persuasive aspects of media use, media reception, and media effects as well as on diffusion, adoption and use of new media. 